\title{
Syringe-Delivered Tumescent Anesthesia Made Easier
}

\author{
Oren Lapid
}

Received: 24 June 2010/Accepted: 29 October 2010/Published online: 24 November 2010

(C) The Author(s) 2010. This article is published with open access at Springerlink.com

\begin{abstract}
A simple method for the infiltration of tumescent anesthesia is presented. An assembly is made using an infusion set, a three-way tap, and two unidirectional valves. The assembly and use of this system are straightforward and easy. The addition of unidirectional valves prevents the risk of reverse injection or aspiration of fluid from the patient.
\end{abstract}

Keywords Tumescent anesthesia $\cdot$ Technical note . Liposuction

Tumescent infiltration achieves effective local anesthesia and a bloodless operative field [1]. Its use is standard practice in liposuction but has also been applied to other procedures, including cosmetic, reconstructive, and burn surgery [2-5]. The basic principle common to all techniques is the delivery of a large amount of fluid with a local anesthetic and a vasoconstrictor. This results in swelling, i.e., tumescence, of the operative field.

Many techniques for the infiltration of the fluid have been described ranging from repeated aspiration of fluid into a large syringe followed by its injection into the patient, to the use of motorized irrigation pumps. There are

O. Lapid $(\bowtie)$

Department of Plastic Reconstructive and Hand Surgery,

Academic Medical Center, University of Amsterdam,

Amsterdam, The Netherlands

e-mail: olapid@yahoo.com also automatic manual pumps available. However, these specialized systems are not always available.

The use of a stopcock three-way tap has been described in the past [6]. The disadvantage of this tap is that it requires two concurrent actions: pumping action using the plunger of the syringe and coordinated turning of the stopcock tap in order to either aspirate fluid from the infusion bag or inject it into the patient. The fluid can be injected in the wrong direction back into the IV bag or it can be aspirated out of the patient.

\section{Technique}

The drawbacks associated with the use of the three-way tap can be addressed by using two unidirectional back-check valves (B. Braun Melsungen AG, Melsungen, Germany); which can be used with the intravenous delivery of medications to avoid backflow. One valve is placed on the IV piping on the input side of the stopcock and the other valve is connected before the infiltration needle. The tap is left open in all three directions. Using reciprocating movements of the plunger of the syringe, similar to those used on a bicycle pump, the fluid will be pumped only into the patient (Fig. 1).

The infiltration needle can be connected directly to the stopcock, permitting operation by the surgeon; otherwise, extension tubing can be used and the pumping action is performed by the assistant while the surgeon directs the infiltration cannula. The use of a 10-cc syringe is easier and faster than the use of larger-volume and larger-diameter syringes because it requires less force, albeit at the cost of more pumping cycles [7]. The additional cost is low $(<€ 2)$. This system has been used in more than 50 patients without problems. 


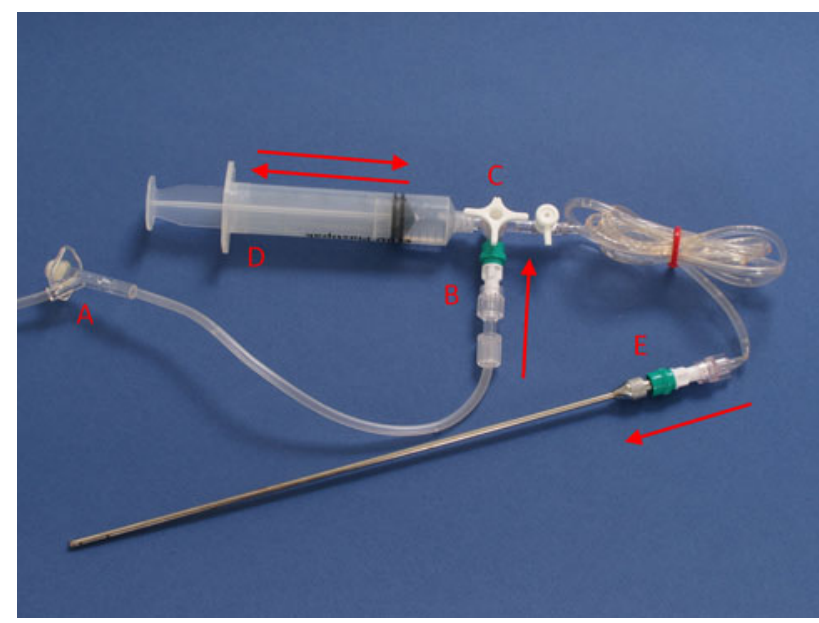

Fig. 1 An assembled device: [A] tubing coming from the bag with fluid, [B] valve preventing backflow to the bag, [C] stopcock threeway tap that has to be open in all directions, [D] syringe with a Luer lock connection, $[\mathrm{E}]$ valve preventing aspiration of fluid back from the patient

\section{Conclusion}

This system has proven to be cheap, simple, and easy to use and implement.

Disclosure The author declares that he has no conflicts of interest or financial ties to disclose.
Open Access This article is distributed under the terms of the Creative Commons Attribution Noncommercial License which permits any noncommercial use, distribution, and reproduction in any medium, provided the original author(s) and source are credited.

\section{References}

1. Kucera IJ, Lambert TJ, Klein JA, Watkins RG, Hoover JM, Kaye AD (2006) Liposuction: contemporary issues for the anesthesiologist. J Clin Anesth 18(5):379-387

2. Robertson RD, Bond P, Wallace B, Shewmake K, Cone J (2001) The tumescent technique to significantly reduce blood loss during burn surgery. Burns 27(8):835-838

3. Mago V, Prasad M (2009) Tumescent local anesthesia for release of postburn neck contractures. J Burn Care Res 30(6):1049

4. Ramon Y, Barak Y, Ullmann Y, Hoffer E, Yarhi D, Bentur Y (2007) Pharmacokinetics of high-dose diluted lidocaine in local anesthesia for facelift procedures. Ther Drug Monit 29(5):644-647

5. Brody GS (1994) The tumescent technique for facelift. Plast Reconstr Surg 94(3):563

6. Aydin HU, Yiğit B, Serin DA, Güven E (2009) A simple setup for easy infiltration of large volumes. Aesthetic Plast Surg 33(1): $129-130$

7. Hodanbosi C (2010) Pascal's principle and hydraulics. Available at http://www.grc.nasa.gov/WWW/k-12/WindTunnel/Activities/ Pascals_principle.html [accessed September 2010] 